\title{
New climate and socio-economic scenarios for assessing global human health challenges due to heat risk
}

\author{
Weihua Dong • Zhao Liu • Hua Liao • Qiuhong Tang • \\ Xian'en Li
}

Received: 31 July 2014 / Accepted: 22 February 2015 /Published online: 11 March 2015

(C) The Author(s) 2015. This article is published with open access at Springerlink.com

\begin{abstract}
Motivated by growing heat-related morbidity and mortality in a warming climate, this paper assesses global heat health risk in order to understand the challenges to sustainability in the 21st century, using four Representative Concentration Pathways (RCPs) of the HadGEM2-ES climate model and five Shared Socio-Economic Pathways (SSPs). Factors influencing global heat health risk were reviewed and risks were estimated based on heat hazard and socio-economic vulnerability. Hazard, vulnerability, risk and in particular, populations at different risk levels, were analyzed quantitatively at both global and regional scales. The results show that under an RCP8.5-SSP3 scenario, the world will be subject to the highest heat health risk, with rapidly increasing hazard levels and vulnerability over the century. Less developed or developing regions, such as Africa and Southeast Asia, are at the highest risk. The heat risk under an RCP2.6-SSP1 scenario will first increase and then fall, resulting in the lowest heat-health-risk pattern. We found that heat health risk will increase during the century under all RCP-SSP scenarios, with a higher frequency, higher intensity, longer duration and
\end{abstract}

Electronic supplementary material The online version of this article (doi:10.1007/s10584-015-1372-8) contains supplementary material, which is available to authorized users.

W. Dong $(\bowtie) \cdot$ Z. Liu $\cdot$ H. Liao $\cdot$ X. Li

State Key Laboratory of Remote Sensing Science, Beijing Key Laboratory for Remote Sensing of Environment and Digital Cities \& School of Geography, Beijing Normal University, Beijing 100875, China e-mail: dongweihua@bnu.edu.cn

Z. Liu

e-mail: liuzhaofairy@gmail.com

H. Liao

e-mail: liaohua@mail.bnu.edu.cn

X. Li

e-mail: lixianen@mail.bnu.edu.cn

Z. Liu

The State Key Laboratory of Earth Surface Processes and Resource Ecology, Beijing Normal University, Beijing 100875, China

Q. Tang

Key Laboratory of Land Surface Pattern and Simulation, Institute of Geographic Sciences and Natural Resources Research, Chinese Academy of Sciences, Beijing 100101, China

e-mail: tangqh@igsnrr.ac.cn 
expanding spatial reach. Significant differences were observed across regions. The results make clear that the increasing risk poses significant challenges to sustainable human health. To meet these challenges, more attention and effective actions are urgently needed from both policy makers and individuals.

\section{Introduction}

Global climate change creates new risks to human health. There is mounting evidence showing that humans have been suffering from a warming planet over a period of years and that this trend will continue. In its Fifth Assessment Report (AR5), the Intergovernmental Panel on Climate Change (IPCC) concluded that the global mean-surface temperature increased $0.85^{\circ} \mathrm{C}$ from 1880 to 2012 and that the temperature is likely to increase by $1.5^{\circ} \mathrm{C}$ compared to the period from 1850 to 1900 by the end of the 21st century (IPCC 2013). Extreme weather events, such as heat waves, are also expected to occur more frequently and with longer duration over most land areas in the late 21st century (Meehl and Tebaldi 2004). Numerous extremely high temperature events with associated mortality worldwide have been reported, such as severe heat waves in Chicago in 1995 (Semenza et al. 1996) and in Europe in 2003 (Robine et al. 2008). Other cases exist in Australia (Vaneckova et al. 2008), Russia (WMO 2013), and China (Tan et al. 2007) as well as in many other areas.

Extremely high temperatures can induce various adverse effects or heat-related diseases (e.g., cardiovascular, cerebrovascular and respiratory disorders) and increase related morbidity and mortality (Barrow and Clark 1998; Bouchama and Knochel 2002; Braga et al. 2002; Fouillet et al. 2006; Hansen et al. 2008; Tian et al. 2013). As indicated by the IPCC report, "the economic and social costs of those events will increase, and these increases will be substantial in the areas most directly affected (IPCC 2007)." It is thus urgent that policy makers are able to predict the high-risk areas and take adaptive measures in response to this trend. This paper presents a preliminary assessment of global heat health risk effects from climate change to identify heat wave challenges to sustainable human health.

\subsection{RCPs and SSPs: new scenarios for future climate and socioeconomic development}

Scenarios have been proposed as effective tools to investigate alternative futures based on existing studies and various assumptions (van Vuuren et al. 2012). For example, the IPCC's SERS scenarios (IPCC 2000) are widely used projections that characterize future climate change and socio-economic development. In SERS, socio-economic development determines future greenhouse gas (GHG) and aerosol emissions, matching each climate scenario with its corresponding socio-economic storyline. Since AR5, a new "parallel" methodology was adopted to produce new scenarios, and thereby new climate scenarios, the so-called Representative Concentration Pathways (RCPs), which are no longer linked to any socioeconomic scenarios. RCPs consist of four pathways modeled as a basis for future climate research and assessment according to atmospheric radiative forcing, covering a period up to the year 2100 (van Vuuren et al. 2011). The four RCPs include RCP2.6 (very low GHG emission), RCP4.5 (intermediate stabilization), RCP6.0 (high stabilization) and RCP8.5 (very high emission), with each representing a pathway based on simulated influences of land use and emissions of air ingredients and greenhouse gases. RCP2.6 describes a very low GHGemission scenario, with radiative forcing at $2.6 \mathrm{~W} / \mathrm{m}^{2}$ by 2100, and so on (Moss et al. 2010).

Shared Socioeconomic Pathways (SSPs) provide reference scenarios describing the development of society and the natural environment, with the assumption that no climate change or 
climate impacts occur and that no climate policies are adopted at a global scale over the course of the 21st century (O'Neill et al. 2014). Five SSP scenarios were defined that employ the mitigation and adaptation to socio-economic challenges: SSP1 3 refers to low, intermediate and high challenges, respectively; SSP4 and SSP5 denote dominating adaptation challenges and dominating mitigation challenges, respectively (Kriegler et al. 2012; O'Neill et al. 2014). Five SSPs and four RCPs can produce $5 \times 4$ scenario combinations that provide plausible bases for heat-risk assessment, although some combinations (e.g., SSP1-RCP8.5) are unlikely to occur in the future (van Vuuren et al. 2014).

\subsection{Vulnerability of different populations}

Vulnerability refers to the extent that a given population may suffer harm from exposure to a hazard related to various socio-economic and demographic characteristics. However, some vulnerability indices are complicated and difficult to measure quantitatively. General vulnerability analysis of sustainability assessments includes exposure, sensitivity, resilience, and adaptive capacity (Turner et al. 2003; van Vuuren et al. 2012). Several vulnerability indices of environmental hazards have been proposed, such as the SoVI (Cutter et al. 2003), EHVI (Johnson et al. 2012), and PVI (Adger 2006). A number of social vulnerability factors have been identified in local- or city-level heat health risk assessments, such as age, poverty, social isolation, education, ethnicity, and access to transportation (Schwartz 2005; Semenza et al. 1996; Vescovi et al. 2005). In this paper, we have identified four indicators of the presence of a vulnerable population:

(1) High population density is closely correlated to higher risk (Dolney and Sheridan 2006; Hajat and Kosatky 2010; Harlan et al. 2006; Medina-Ramon and Schwartz 2007). This correlation may be explained by the phenomenon that high population density is located in urban areas that have higher temperatures because inner-city areas are affected by the urban heat island (UHI) effect (Tomlinson et al. 2011). High population density regions have more human activity such as vehicle and air-conditioning use that contributes to the local heat island (Luber and McGeehin 2008; Smith et al. 2009).

(2) Elderly people have lower adaptation ability and higher mortality rates (Poumadère et al. 2005; Vescovi et al. 2005; CDC 2002; Pan et al. 1995). Older people have decreasing regulatory abilities for intrinsic homeostasis, making them insensitive to temperature changes and unaware of becoming ill (Koppe et al. 2004). Elderly-related diseases (e.g., coronary heart disease and cerebral infarction) increase their mortality, and their lower mobility prevents them from taking countermeasures to reduce their exposure. Furthermore, a higher incidence of isolation contributes to the absence of daily care and efficient help in emergency situations.

(3) Economic or income levels indicate the mitigation ability of individuals and governments to the hazard. For individuals, income level affects building and housing features, for example, air-conditioning use, which is considered a protective measure for urban populations from heat exposure (Lundgren and Kjellstrom 2013). A study of the Missouri heat wave in 1980 shows that the possibility of heatstroke in low-income groups was six times that of high-income groups (Jones et al. 1982). Low income is associated with fewer opportunities to assess useful information and resources and less awareness of self-protection during heat waves (Blaikie et al. 2004). At the level of both country and city, economic health, or gross domestic product (GDP), is likely linked with infrastructure construction and risk-management level that are critical to quick responses and recovery when a hazard occurs. Hajat and Kosatky (2010) found that the lower GDP of cities contributed to higher heat health risks. 
(4) Education level is an indicator of vulnerability (Cutter et al. 2003; Johnson et al. 2009; Vescovi et al. 2005), because educational attainment can significantly affect individuals' resilience, as it is related to a higher awareness and better knowledge of hazard prevention. It is also assumed that people with higher education levels can find better employment and access to assistance programs (Morrow 1999). Higher educational attainment allows for an improved quality of life (O’Neill et al. 2003). Higher mortality rates have also been observed among less-educated people.(Steenland et al. 2002). Furthermore, the proportion of a population with higher education is a sign of technological strength, which is an important indicator of the ability to mitigate and adapt to climate change.

\section{Methods}

\subsection{Assessment of heat health risk}

This study measures heat health risk simply as the product of hazard and vulnerability (Eq. (1), UNDRO 1991; Tomlinson et al. 2011; Vescovi et al. 2005) using the geographic information system (GIS).

$$
\text { Risk }=\text { Hazard } \times \text { Vulnerability }
$$

where Hazard and Vulnerability are calculated below. Both Hazard and Vulnerability are normalized to $0-1$ using maximum and minimum values across all scenarios and years.

\subsection{Heat hazard}

Defining the temperature threshold for heat events is a key step in risk assessment, but there is no consistent standard in the existing literature. Studies typically define heat waves as exceeding fixed absolute values or deviations from the normal (Robinson 2001). For example, the US National Weather Service (NWS) suggests a $T_{\max }$ (daily maximum temperature) of $\geq 40.6^{\circ} \mathrm{C}\left(105^{\circ} \mathrm{F}\right)$ for excessive heat warning (NWS 2015), while the Netherlands uses a period during which $T_{\max }>25^{\circ} \mathrm{C}$ for $\geq 5$ days, provided that at least 3 days in this period have a $T_{\max }>30{ }^{\circ} \mathrm{C}$ (Garssen et al. 2005). This paper holds that an absolute threshold is inappropriate on a global scale because the acclimatization of populations in different regions differs significantly for physiological, behavioral and cultural reasons (Kovats and Hajat 2008). For example, a study of the vulnerability curves in 11 US cities showed that the higher the latitude, the lower the tolerance to high temperature (Curriero et al. 2002). Therefore, a relative threshold definition, described below, is adopted to define heat waves.

To quantify the heat hazard, we used the number of heat wave days defined as the number of days that exceed the threshold for at least six consecutive days. The threshold is defined as the local 90th percentile of daily maximum temperatures over the period 1971-2000 (Fischer and Schär 2010). If the local 90th percentile is lower than $25^{\circ} \mathrm{C}$, we use $25^{\circ} \mathrm{C}$ as the threshold (Garssen et al. 2005). The daily maximum temperature data were obtained from the biascorrected climate data (Hempel et al. 2013) from the HadGEM2-ES model (Jones et al. 2011) under 4 RCPs, which are available from the Inter-Sectoral Impact Model Intercomparison Project (ISI-MIP: http://esg.pik-potsdam.de) (Warszawski et al. 2014). 


\subsection{Socio-economic vulnerability}

The socio-economic data were obtained from the ISI-MIP (http://clima-dods.ictp.it/d10/ fcolon_g/ISI-MIP), which includes five SSP scenarios, namely SSP 1-5. The SSP-scenario data provide four sub-indices:

(1) Population density (PopDen) with a spatial resolution of $0.5^{\circ}$.

(2) Percent of population aged over 65 (AgedPop) in an administrative unit at the country level.

(3) Per capita GDP $(G D P)$ in an administrative unit at the country level.

(4) Education level $(E d u)$, measured by the percentage of the population with higher education in an administrative unit at the country level.

The four factors were combined into the final vulnerability formula using Eq. (2):

$$
\text { Vulnerability }=\frac{1}{3}[\text { AgedPop }+(1-G D P)+(1-E d u)] \times \text { PopDen }
$$

The symbols are defined above. Although the literature shows that the contribution of social indices differs and that autocorrelation exists among them, there is no commonly acknowledged standard for each index and for this reason, we combined these indices with equal weight (Cutter et al. 2003; Reid et al. 2009; Johnson et al. 2012). Pixels that mean population density is lower than $1 / \mathrm{km}^{2}$ are excluded from the calculation. A base 10 logarithm of population density is applied before normalization.

\section{Results}

\subsection{Hazard}

The heat wave area, calculated as the area with heat wave divided by the total land area excluding Greenland and other areas with missing values, will grow continually under all RCP scenarios (Supplementary Fig.1a). RCP8.5 shows both a rapid increase and that the heat-wave area will reach near $85 \%$ of land surface by 2100 . RCP 2.6 will first increase and then stabilize at a level of $70 \%$ after the mid-century. The RCP4.5 and RCP6.0 scenarios fall in between RCP8.5 and RCP2.6. Statistics show that by 2100 , the number of heat-wave days will exceed 80 per year under the RCP2.6 scenario and 280 per year under the RCP8.5 scenario in the areas between $10^{\circ} \mathrm{N}$ and $20^{\circ} \mathrm{S}$ and will spatially decrease to the two poles (Supplementary Fig. 1b).

By the late 21st century, the global mean number of heat-wave days under the RCP8.5 scenario will exceed 100, whereas the number will be less than 50 under the 2.6 scenario (see lower panel in Fig. 2). At the regional scale, the value in Africa and South America will exceed 200 by 2100 under the RCP8.5 scenario, while Asia and Australia will reach nearly 100, and Europe and North America will exceed 60. The RCP6.0 scenario shows a relatively lower growth speed and the value reaches more than 150 in Africa and South America and more than 40 in other continents. In contrast, the RCP2.6 scenario exhibits a slight rise and then stabilizes at approximately 50 days in all continents over the course of the century. Values have some fluctuation for each continent, but it is much higher in South America than in the other continents. 


\subsection{Vulnerability}

Combining four factors (i.e., population, older population, per capita GDP and education, see Supplementary Fig. 2) into vulnerability, SSP3 has the most vulnerable population and the vulnerability continues to grow, followed by SSP4 and SSP2. SSP1 and SSP5 display an increasing tendency and reach their peaks in 2075 before decreasing. The interannual variance and spatial distribution of vulnerability show similarities across all SSP scenarios (Supplementary Fig. 3). It can be seen that China and India, which have the largest populations in the world, maintain high vulnerability through the century. By 2100 , the most vulnerable areas include most of India, parts of east China and sub-Saharan Africa, followed by most of Europe, parts of Central Africa, Asia, eastern parts of North America, Central America and South America.

Significant differences in vulnerability across regions are observed at the regional scale (Fig. 2). Generally, regions can be divided into three classes according to their numerical values of vulnerability: high (Africa, Asia and Europe), medium (North America and South America) and low (Australia). Furthermore, the trends differ significantly between scenarios. Under the SSP3 scenario, the mean vulnerability of Europe will experience a clear reduction, but the descending range is small; mean vulnerability for Asia, North America and Australia will maintain a steady state, and the vulnerability of Africa and South America will increase continuously and rapidly, most dramatically in Africa. In contrast, under the SSP1 scenario, vulnerability will decrease continuously in more continents, including Europe, Asia, South America and Australia. Except for Europe, the descending ranges are small in these continents and they all first grow and then decrease after 2050. Only Africa will experience an increasing trend of vulnerability and only North America will experience a stable trend under the SSP1 scenario. The variation trends of each continent will be between SSP1 and SSP3. Comparing the vulnerability under all three SSP scenarios in different regions, only Africa will increase under all scenarios, and it also has the highest growth rate. The global mean vulnerability is between 0.3 and 0.4 under all scenarios. Under SSP3, vulnerability will increase to 0.35 by 2100. Under the remaining two scenarios, vulnerability will increase in the first stage and then decrease to the 2010 level.

\subsection{Heat health risk at the global and regional scales}

Three combinations (namely, RCP2.6-SSP1, RCP6.0-SSP2, and RCP8.5-SSP3) are selected for further analysis that are also consistent with scenarios in SRES (RCP6.0-SSP2 $\approx \mathrm{B} 2$, $\mathrm{RCP} 8.5-\mathrm{SSP} 3 \approx \mathrm{A} 2$, no corresponding scenario to RCP2.6 in SRES).

\subsubsection{Spatial distribution of risk}

Figure 1 shows that, generally and unsurprisingly, the highest risk scenario combination is RCP8.5-SSP3, followed by RCP6.0-SSP2, and the lowest is RCP2.6-SSP1. Relatively higher risk areas are distributed between $50^{\circ} \mathrm{N}$ and $30^{\circ} \mathrm{S}$. The lowest risk areas are mainly located beyond $50^{\circ} \mathrm{N}$ in North America and Asia, almost all of Australia, the Sahara, and parts of South Africa and South America.

RCP2.6-SSP1 has the smallest area of (very) high risk among all scenario combinations. As a sustainable and low-emission scenario combination, both hazard under RCP2.6 and vulnerability under SSP1 will reach their peak values before 2100 and decline (see lower panel of Fig. 2), thus the heat health risk exhibits a slight increase compared to the other combinations at a global scale. 

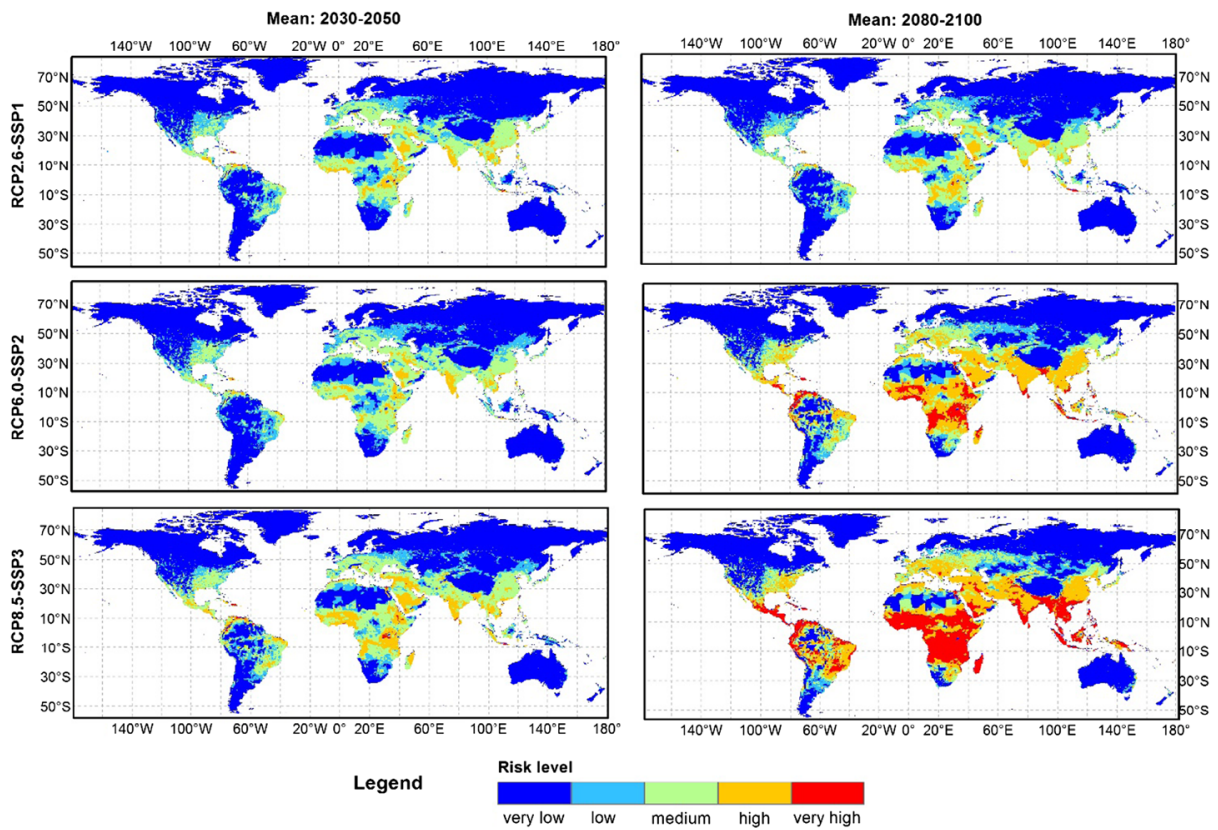

Fig. 1 Spatial distribution of the mean risk at the global scale in the near future (2030-2050) and the long term (20802100). Risk is divided into five classes from very low to very high using break values of $0.03,0.06,0.12$ and 0.24

Under RCP6.0-SSP2 scenarios, the general spatial heat health risk distribution is similar to the distribution under the RCP8.5-SSP3 scenarios, but the average risk is lower. Specifically, very high risk areas are located in undeveloped or developing countries in South Asia (India

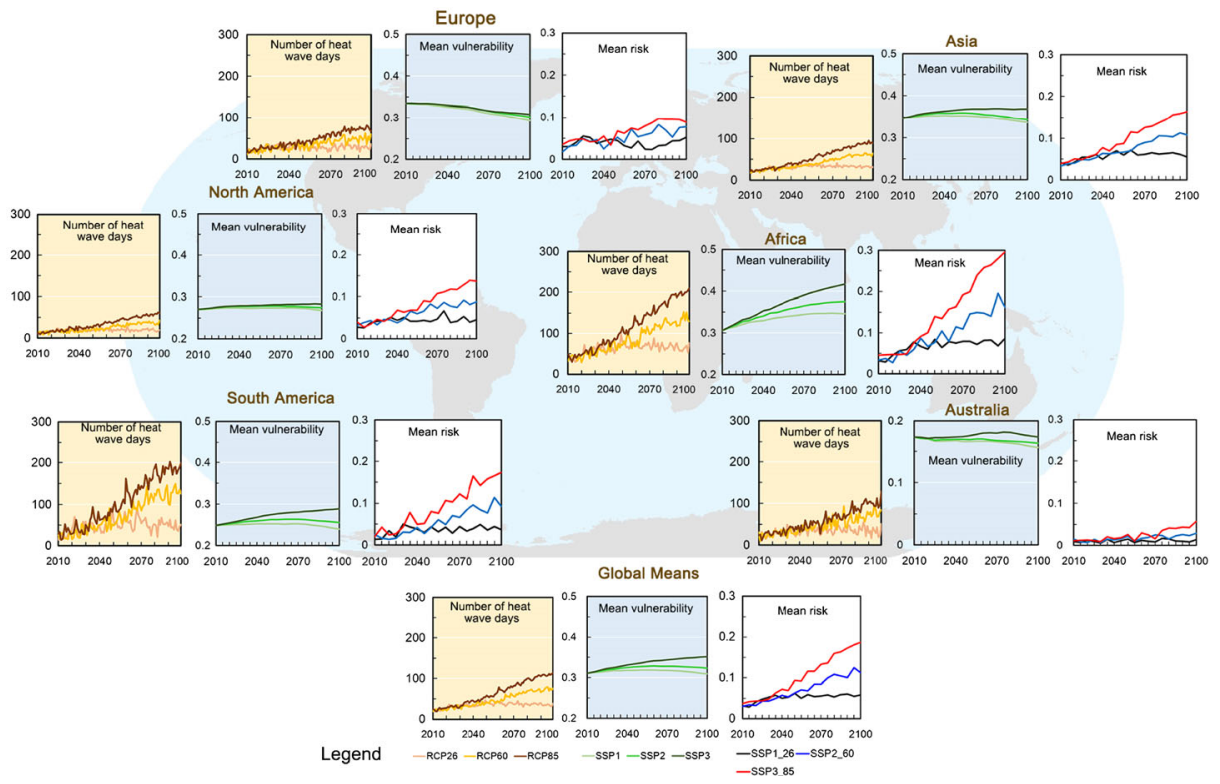

Fig. 2 Hazard, vulnerability and heat health risk at global and regional scales 
and Pakistan), Africa (Nigeria, Ghana, Burkina Faso, Tanzania, and Uganda), and Asia (China, Indonesia, and Philippines), and very high risk areas in China will expand by 2050 and then shrink by 2100 . This may be because GDP grows rapidly with a decreasing older population after reaching a peak value in the mid-21st century.

High heat health risk areas will expand significantly under the RCP8.5-SSP3 scenarios. In the near future, the very high risk areas include some small fragmentary regions in South America and Africa. From 2050 to 2100, the heat health risk will increase rapidly in these areas as well as parts of South Asia, Southeast Asia and Central America. High risk areas are mainly distributed around very high risk areas in Europe, West Asia, East Asia and North America.

\subsubsection{Risk at the regional scale}

At the regional scale, significant differences are observed (Fig. 2). Regions can be divided into three classes according to their numerical values of risk: the high-risk class contains only Africa (risk: 0-0.3); the medium-risk class, including North America, South America and Asia (risk: 0-0.2); and the low-risk class, including Australia and Europe (risk: 0-0.1). In the first class, Africa suffers from rapidly increasing risk under RCP8.5-SSP3 and RCP6.0-SSP2 due to the high hazard and rapid growth of vulnerability, reaching 0.3 and 0.2 until the end of the 21 st century, respectively. Compared to Africa, the risk of North America, South America and Asia increases more slowly and peaks at $0.15,0.18$ and 0.16 by 2100 under RCP8.5-SSP3, respectively, while under RCP2.6-SSP1, these three regions experience low and stable risk levels ( 0.5 or lower) over the century. In the third class, Australia proceeds with stable risk under all RCP-SSP combinations and has the lowest risk among all regions.

\subsubsection{Populations at risk}

Figure 3 and Supplementary Table 1 show populations at different levels of heat health risk at the global and regional scale. The global population at very high risk increases under RCP6.0-SSP2 and RCP8.5-SSP3, reaching nearly 3.4 billion and 10 billion, or 38 and $76 \%$ of the world population, by 2100 , respectively. Under RCP2.6-SSP1, this value reaches 0.3 billion (5\%). In contrast, populations at low and very low risk decrease throughout the century.

At the regional scale, the populations with a very high level of risk vary from dozens/hundreds of millions (Europe, North America, and South America) to billions (Africa and Asia). As the population of both Africa and Asia reaches over 5 billion, the very high-risk population grows to 5 billion $(94 \%)$ and 4 billion (72\%) under RCP8.5-SSP3 by the end of this century, respectively. Under RCP6.0-SSP2, the values exceed 2 billion and 0.9 billion in these two regions while RCP2.6-SSP1 results in a relatively lower proportion of the population at very high risk. In North America, the very high-risk population reaches 13 (2\%), 153 (25\%) and 381 (65\%) million under RCP2.6-SSP1, RCP6.0-SSP2, and RCP8.5-SSP3, respectively. The population in South America is in line with that of North America, with values of $1(0 \%), 97$ (23\%), and $418(61 \%)$, respectively. In Europe, the total population declines over the century. However, the very high-risk population grows. No very high-risk population is observed in Australia. 


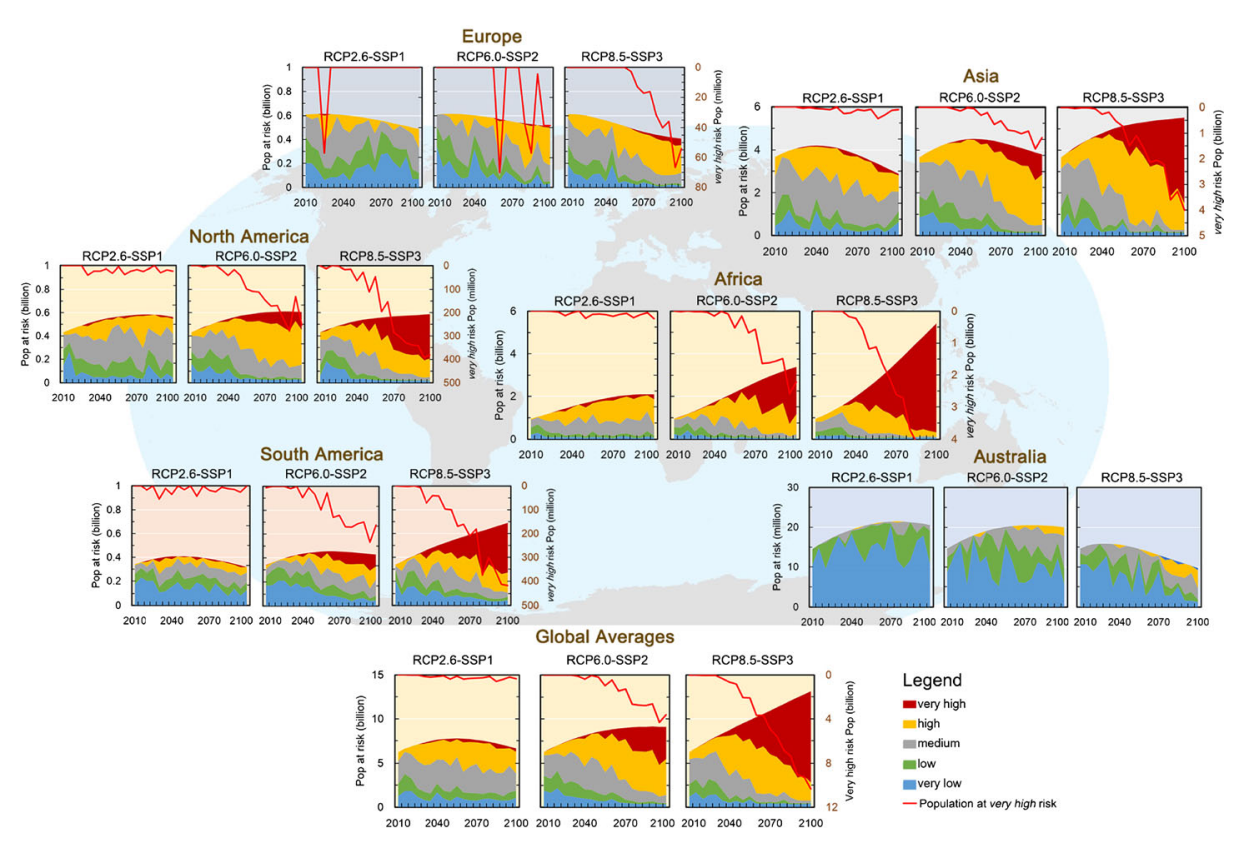

Fig. 3 Populations at different levels of heat health risk at global and regional scales

\section{Discussion}

\subsection{Influence of heat definition}

A challenge faced by heat-wave studies is that no standard definition exists in terms of temperature threshold, metric, and lasting days (Anderson and Bell 2010). In this paper, heat waves are defined as $\geq 6$ days with temperature $\geq 90$ th percentile (90P6D: 90th percentile, 6 days), which focuses on the duration and intensity of heat waves. For comparison, two alternative definitions are used to explore different influences of heat definitions on heat risk: (1) $\geq 3$ days with temperature $\geq 95$ th percentile $(95 \mathrm{P} 3 \mathrm{D}$, shorter but more intense) and (2) $\geq 3$ days with temperature $\geq 30$ centigrade degrees $(30 \mathrm{C} 3 \mathrm{D}$, shorter and threshold fixed). We use heat-wave area (\%) and global mean risk to compare hazard and risk results across these three definitions, respectively.

The 90P6D and fixed-threshold 30C3D yield a very similar trend of heat wave area (Fig. 4a) while 95P3D produces significantly higher values than 90P6D under all scenarios (Fig. 4b). This indicates that shorter but more intense heat waves are likely to occur in more land areas than lower intensity but longer lasting heat waves. For global mean risk, relative temperature threshold definitions (90P6D and 95P3D) exhibit a slight difference, with 95P3D lower than 90P6D in magnitudes of 0.01 (Fig. 4c). But the fixed-threshold definition shows significantly higher risk than the other two definitions, which is consistent with the spatial distribution of heat risk (Supplementary Fig. 4). Since hazard is normalized before calculating the final risk, the relative threshold definition 95P3D produces nearly the same risk-assessment results as $90 \mathrm{P} 6 \mathrm{D}$, although it differs significantly in terms of hazard. 
(a) Heat wave area comparison: 90P6D - 30C3D

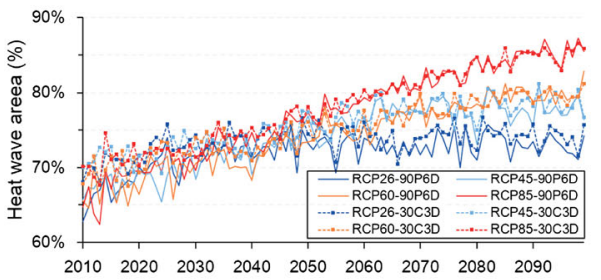

(b) Heat wave area comparison: 90P6D - 95P3D

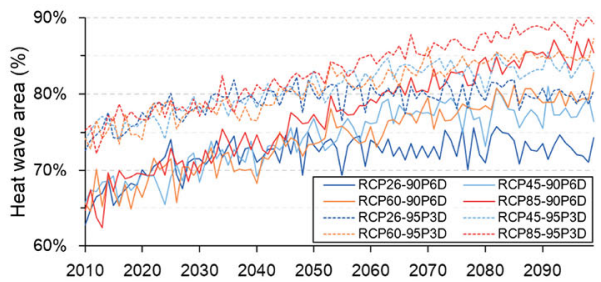

(c) Global mean risk comparison: 90P6D - 95P3D - 30C3D

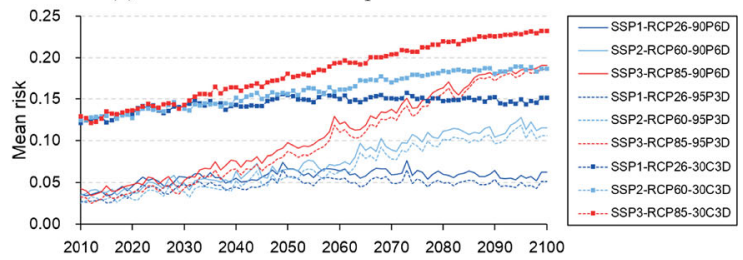

Fig. 4 Comparison of the influences of different heat definitions on risk

4.2 Influences of correlation and weights of vulnerability factors on risk

Another challenge is that a correlation exists in the vulnerability analysis. Cutter et al. (2003) presented a general index called social vulnerability index (SoVI), which listed 42 variables and reduced them to 11 independent factors that account for $76 \%$ of the variance. Johnson et al. (2012) developed an extreme heat vulnerability index (EHVI) that contains the principal components of 25 census data and remotely sensed variables that explain $80 \%$ of the total variance. In this study, a correlation analysis is conducted temporally (using global means from 2010 to 2100 for a given SSP) and spatially (using country values for a given year and an SSP). Results show that temporally, Edu, Aged, and GDP are significantly correlated, while $E d u$ and Aged are spatially correlated across years and SSPs (Supplementary Fig. 5). Although the numeric values of these factors seem to be represented by one or more common variable(s) using factor analysis, they present different aspects of vulnerability and therefore, are employed in the assessment.

Multiple studies have used the equal weight method to calculate vulnerability (e.g., Collins et al. 2009; Tomlinson et al. 2011; Vescovi et al. 2005; Dong et al. 2014). To compare the influence of the weight variance of vulnerability factors on heat risk, we computed the global mean risk under the condition that the weight of Aged ranges from 0.1 to 0.9 (step: 0.1 ) by the ratio of weight $(G D P)$ and weight $(e d u)$ ranges from 0.1 to 0.9 (step: 0.1$)$ and 1 to 10 (step: 1). The results show that although the weight variance of vulnerability factors affects the vulnerability significantly (Supplementary Fig. 6), it has marginal influence on the final risk (with the mean risk variance at the 0.001-0.01 magnitude level) compared to the 0.1 magnitude level of global mean risk (Supplementary Figs. 6-8), because vulnerability has been normalized temporally and spatially.

\subsection{Statistical analysis of historic heat waves and the estimated heat risk}

The European heat wave of 2003 is selected to validate our heat-risk assessment method. Data of historic heat-wave related deaths of fourteen European countries are extracted from the Emergency Events Database (EM-DAT: http://www.emdat.be/). Statistical results show that 
the death toll and the estimated risk are significantly correlated (Supplementary Fig. 9). The R square of linear regression of $90 \mathrm{P} 6 \mathrm{D}, 95 \mathrm{P} 3 \mathrm{D}$ and $30 \mathrm{C} 3 \mathrm{D}$ is $0.86,0.72$, and 0.49 , respectively. A further correlation analysis shows that the various weights of vulnerability factors have no significant influence on the correlation, as we expected from the results of Section 4.2 (Supplementary Fig. 10).

It should be noted that high mortality in historical heat waves was not fully due to high temperatures. Anderson and Bell (2009) showed that acclimatization, individual susceptibility, and community characteristics all have heat-related impacts on mortality. Furthermore, heat-related mortality is affected not only by the intensity and duration of heat waves, but also by other indirect social factors (Anderson and Bell 2010). In this paper, heat intensity and duration are modeled in hazard while some social factors (age, education, and GDP) are measured in vulnerability to assess the heat risk. However, other factors, including air humidity and air pollutants, are beyond the scope of this study and merit future investigation.

\section{Conclusions}

This paper assessed global heat health risk during the 21 st century using new climate and socio-economic scenarios. Hazard, vulnerability and risk were analyzed at the global and regional scale. The results show that under RCP8.5-SSP3 scenarios, the world will be at the highest heat health risk with rapidly increasing hazard levels and vulnerability through 2100. Less developed or developing regions, such as Africa, Southeast Asia, South Asia and Middle America, are at the highest risk. The RCP2.6-SSP1 scenarios show a rise first and then a falling level of risk, resulting in the lowest heat health risk level. RCP6.0-SSP2 falls between these two scenarios. The proportion of global population that is at very high risk increases, while the population at low and very low risk decreases over the century.

Significant differences are observed in the hazards, vulnerability, risk and populations at different levels of risk across regions. The heat-wave area expands to high latitudes and the number of heat-wave days grows. Africa, Asia, Europe and Middle America show a relatively higher vulnerability, while North America, North Asia and Australia exhibit lower levels. Under three RCP-SSP scenario combinations, Africa, Asia, North America and South America proceed with higher and rapidly growing heat-health risk, while Australia experiences lower risk. Europe falls in between these two outcomes. Furthermore, Africa and Asia will experience a rapidly increasing population at the very high risk level, upwards of billions of people by the end of the century. Other regions, except Australia, will also experience a growing population considered to be at very high risk.

Heat health risk will increase over this century under all RCP-SSP scenarios, and the extent varies depending on socio-economic variables. Although uncertainties exist, the sustainability of global human health requires attention and action from both policy makers and individuals.

Acknowledgments This research was supported by the National Basic Research Program of China (973 Program) (Grant No. 2012CB955403) and National Natural Science Foundations of China (NSFC, Grant No. 41471382). Comments from the reviewers are appreciated, which helped in the improvement of the article's quality. All the climate and socio-economic data used in this study are available at the ISI-MIP ESGF Node (http://esg.pik-potsdam.de). 
Open Access This article is distributed under the terms of the Creative Commons Attribution License which permits any use, distribution, and reproduction in any medium, provided the original author(s) and the source are credited.

\section{References}

Adger WN (2006) Vulnerability. Glob Environ Chang 16:268-281

Anderson BG, Bell ML (2009) Weather-related mortality: how heat, cold, and heat waves affect mortality in the United States. Epidemiology (Cambridge, Mass) 20:205

Anderson BG, Bell ML (2010) Heat waves in the United States: mortality risk during heat waves and effect modification by heat wave characteristics in 43 U. S. communities. Environ Health Perspect 119:210-218

Barrow MW, Clark KA (1998) Heat-related illnesses. Am Fam Physician 58:749-756

Blaikie P, Cannon T, Davis I, Wisner B (2004) At risk: natural hazards, people's vulnerability and disasters. Psychology Press

Bouchama A, Knochel JP (2002) Heat stroke. N Engl J Med 346:1978-1988

Braga AL, Zanobetti A, Schwartz J (2002) The effect of weather on respiratory and cardiovascular deaths in 12 US cities. Environ Health Perspect 110:859

CDC (Centers for Disease Control and Prevention) (2002) Heat-related deaths-four states, July-August 2001, and United States, 1979-1999. MMWR Morb Mortal Wkly Rep 51:567

Collins TW, Grineski SE, de Lourdes Romo Aguilar M (2009) Vulnerability to environmental hazards in the Ciudad Juárez (Mexico)-El Paso (USA) metropolis: a model for spatial risk assessment in transnational context. Appl Geogr 29:448-461

Curriero FC, Heiner KS, Samet JM, Zeger SL, Strug L, Patz JA (2002) Temperature and mortality in 11 cities of the eastern United States. Am J Epidemiol 155:80-87

Cutter SL, Boruff BJ, Shirley WL (2003) Social vulnerability to environmental hazards. Soc Sci Q 84:242-261

Dolney TJ, Sheridan SC (2006) The relationship between extreme heat and ambulance response calls for the city of Toronto, Ontario, Canada. Environ Res 101:94-103

Dong W, Liu Z, Zhang L, Tang Q, Liao H, Li X (2014) Assessing heat health risk for sustainability in Beijing's urban heat island. Sustainability 6:7334-7357

Fischer E, Schär C (2010) Consistent geographical patterns of changes in high-impact European heatwaves. Nat Geosci 3:398-403

Fouillet A, Rey G, Laurent F, Pavillon G, Bellec S, Guihenneuc-Jouyaux C, Clavel J, Jougla E, Hemon D (2006) Excess mortality related to the August 2003 heat wave in France. Int Arch Occup Environ Health 80:16-24

Garssen J, Harmsen C, Beer JD (2005) The effect of the summer 2003 heat wave on mortality in the Netherlands. Euro Surveill 10:165-167

Hajat S, Kosatky T (2010) Heat-related mortality: a review and exploration of heterogeneity. J Epidemiol Community Health 64:753-760

Hansen AL, Bi P, Ryan P, Nitschke M, Pisaniello D, Tucker G (2008) The effect of heat waves on hospital admissions for renal disease in a temperate city of Australia. Int J Epidemiol 37:1359-1365

Harlan SL, Brazel AJ, Prashad L, Stefanov WL, Larsen L (2006) Neighborhood microclimates and vulnerability to heat stress. Soc Sci Med 63:2847-2863

Hempel S, Frieler K, Warszawski L, Schewe J, Piontek F (2013) A trend-preserving bias correction-the ISI-MIP approach. Earth Syst Dyn 4:219-236

IPCC (2000) Special report on emissions scenarios. Cambridge University Press, Cambridge

IPCC (2007) Summary for policymakers. In: Climate change 2007: impacts, adaptation and vulnerability. Cambridge University Press, Cambridge, UK, 7-22

IPCC (2013) Summary for policymakers. In: Climate change 2013: the physical science basis. Cambridge University Press, Cambridge, United Kingdom and New York, NY, USA.

Johnson DP, Wilson JS, Luber GC (2009) Socioeconomic indicators of heat-related health risk supplemented with remotely sensed data. Int J Health Geogr 8:57

Johnson DP, Stanforth A, Lulla V, Luber G (2012) Developing an applied extreme heat vulnerability index utilizing socioeconomic and environmental data. Appl Geogr 35:23-31

Jones TS, Liang AP, Kilbourne EM, Griffin MR, Patriarca PA, Wassilak SG, Mullan RJ, Herrick RF, Donnell HD Jr, Choi K, Thacker SB (1982) Morbidity and mortality associated with the July 1980 heat wave in St Louis and Kansas City, Mo. JAMA 247:3327-3331

Jones C, Hughes J, Bellouin N, Hardiman S, Jones G, Knight J, Liddicoat S, O’Connor F, Andres RJ, Bell C (2011) The HadGEM2-ES implementation of CMIP5 centennial simulations. Geosci Model Dev 4:543-570 
Koppe C, Kovats S, Jendritzky G, Menne B, Breuer DJ, Wetterdienst D (2004) Heat waves: risks and responses. Regional Office for Europe, World Health Organization

Kovats RS, Hajat S (2008) Heat stress and public health: a critical review. Annu Rev Public Health 29:41-55

Kriegler E, O'Neill BC, Hallegatte S, Kram T, Lempert RJ, Moss RH, Wilbanks T (2012) The need for and use of socio-economic scenarios for climate change analysis: a new approach based on shared socio-economic pathways. Glob Environ Chang 22:807-822

Luber G, McGeehin M (2008) Climate change and extreme heat events. Am J Prev Med 35:429-435

Lundgren K, Kjellstrom T (2013) Sustainability challenges from climate change and air conditioning use in urban areas. Sustainability 5:3116-3128

Medina-Ramon M, Schwartz J (2007) Temperature, temperature extremes, and mortality: a study of acclimatisation and effect modification in 50 US cities. Occup Environ Med 64:827-833

Meehl GA, Tebaldi C (2004) More intense, more frequent, and longer lasting heat waves in the 21st century. Science 305:994-997

Morrow BH (1999) Identifying and mapping community vulnerability. Disasters 23:1-18

Moss RH, Edmonds JA, Hibbard KA, Manning MR, Rose SK, van Vuuren DP, Carter TR, Emori S, Kainuma M, Kram T, Meehl GA, Mitchell JF, Nakicenovic N, Riahi K, Smith SJ, Stouffer RJ, Thomson AM, Weyant JP, Wilbanks TJ (2010) The next generation of scenarios for climate change research and assessment. Nature 463:747-756

O'Neill BC, Kriegler E, Riahi K, Ebi KL, Hallegatte S, Carter TR, Mathur R, van Vuuren DP (2014) A new scenario framework for climate change research: the concept of shared socioeconomic pathways. Clim Chang 122:387-400

O'Neill MS, Zanobetti A, Schwartz J (2003) Modifiers of the temperature and mortality association in seven US cities. Am J Epidemiol 157:1074-1082

Pan WH, Li LA, Tsai MJ (1995) Temperature extremes and mortality from coronary heart disease and cerebral infarction in elderly Chinese. Lancet 345:353-355

Poumadère M, Mays C, Le Mer S, Blong R (2005) The 2003 heat wave in France: dangerous climate change here and now. Risk Anal 25:1483-1494

Reid CE, O'Neill MS, Gronlund CJ, Brines SJ, Diez-Roux AV, Brown DG, Schwartz JD (2009) Mapping community determinants of heat vulnerability. 117:1730-1736

Robine JM, Cheung SL, Le Roy S, Van Oyen H, Griffiths C, Michel JP, Herrmann FR (2008) Death toll exceeded 70,000 in Europe during the summer of 2003. C R Biol 331:171-178

Robinson PJ (2001) On the definition of a heat wave. J Appl Meteorol 40:762-775

Schwartz J (2005) Who is sensitive to extremes of temperature?: a case-only analysis. Epidemiology $16: 67-72$

Semenza JC, Rubin CH, Falter KH, Selanikio JD, Flanders WD, Howe HL, Wilhelm JL (1996) Heat-related deaths during the July 1995 heat wave in Chicago. N Engl J Med 335:84-90

Smith C, Lindley S, Levermore G (2009) Estimating spatial and temporal patterns of urban anthropogenic heat fluxes for UK cities: the case of Manchester. Theor Appl Climatol 98:19-35

Steenland K, Henley J, Thun M (2002) All-cause and cause-specific death rates by educational status for two million people in two American Cancer Society cohorts, 1959-1996. Am J Epidemiol 156:11-21

Tan J, Zheng Y, Song G, Kalkstein LS, Kalkstein AJ, Tang X (2007) Heat wave impacts on mortality in Shanghai, 1998 and 2003. Int J Biometeorol 51:193-200

Tian Z, Li S, Zhang J, Guo Y (2013) The characteristic of heat wave effects on coronary heart disease mortality in Beijing, China: a time series study. PLos One 8:e77321

Tomlinson C, Chapman L, Thornes J, Baker C (2011) Including the urban heat island in spatial heat health risk assessment strategies: a case study for Birmingham, UK. Int J Health Geogr 10:42

Turner BL, Kasperson RE, Matson PA, McCarthy JJ, Corell RW, Christensen L, Eckley N, Kasperson JX, Luers A, Martello ML, Polsky C, Pulsipher A, Schiller A (2003) A framework for vulnerability analysis in sustainability science. Proc Natl Acad Sci 100:8074-8079

UNDRO (United Nations Disaster Relief Organization) (1991) Mitigating natural disasters : phenomena, effects and options : a manual for policy makers and planners. United Nations, New York

van Vuuren DP, Edmonds J, Kainuma M, Riahi K, Thomson A, Hibbard K, Hurtt G, Kram T, Krey V, Lamarque J-F, Masui T, Meinshausen M, Nakicenovic N, Smith S, Rose S (2011) The representative concentration pathways: an overview. Clim Chang 109:5-31

van Vuuren DP, Riahi K, Moss R, Edmonds J, Thomson A, Nakicenovic N, Kram T, Berkhout F, Swart R, Janetos A, Rose SK, Arnell N (2012) A proposal for a new scenario framework to support research and assessment in different climate research communities. Glob Environ Chang 22:21-35

van Vuuren DP, Kriegler E, O'Neill B, Ebi K, Riahi K, Carter T, Edmonds J, Hallegatte S, Kram T, Mathur R, Winkler H (2014) A new scenario framework for climate change research: scenario matrix architecture. Clim Chang 122:373-386 
Vaneckova P, Beggs PJ, de Dear RJ, McCracken KW (2008) Effect of temperature on mortality during the six warmer months in Sydney, Australia, between 1993 and 2004. Environ Res 108:361-369

Vescovi L, Rebetez M, Rong F (2005) Assessing public health risk due to extremely high temperature events: climate and social parameters. Clim Res 30:71-78

Warszawski L, Frieler K, Huber V, Piontek F, Serdeczny O, Schewe J (2014) The Inter-Sectoral Impact Model Intercomparison Project (ISI-MIP): project framework. Proc Natl Acad Sci 111:3228-3232

NWS (National Weather Service) (2015) Regional warning, watch, and advisory criteria. [cited 2015/01/15]; Available from: http://www.weather.gov/ctp/wwaCriteria

WMO (World Meteorological Organization) (2013) The global climate 2001-2010: a decade of climate extremes summary report. [cited 2014/05/05]. Available from: http://www.unep.org/pdf/wmo_report.pdf 